\title{
In-Plane Compression of Constrained Preforms
}

\author{
DAVID A. NORMAN, JAE-HO KIM, and RICHARD E. ROBERTSON* \\ Department of Materials Science and Engineering \\ University of Michigan \\ Ann Arbor, MI 48109-2136
}

\begin{abstract}
Preforms constructed from a plain-weave, glass fabric were compressed in-plane within a fixture that mimicked the constraints of a closed mold. Typically, a gap was left between the bottom of the preform and the floor of the fixture; upon initial compression, the preform slid within the fixture, which allowed the friction between the preform and the fixture wall to be measured. The preform began to compress as it contacted the floor of the fixture. The deformation was proportional to the applied stress until a critical stress was reached. Above this stress, the preform sustained damage in the form of localized buckling and a corresponding decrease in mechanical integrity. The in-plane compressive behavior varied with system parameters, such as preform geometry, fabric orientation, and clamping stress and was shown to be strongly dependent on friction of the preform against the fixture wall. A model was developed to describe the contribution of preform friction with the fixture wall to the in-plane compressive behavior of constrained preforms.
\end{abstract}

\section{INTRODUCTION}

$I^{\mathrm{n}}$ mproper preform wetting is a major obstacle to be lovercome in liquid composite molding. Ideally, resin flows through the preform, wetting it completely. However, if small gaps exist between the preform and the mold wall, resin preferentially flows through these and may lead to dry spots. This is known as racetracking or the edge effect; it and the resulting problem are illustrated in Fig. 1. Gaps at the edges may be present as a result of imprecise shaping, cutting, or placement of the preform or because of preform deformation by high-pressure injection of the resin. Attempts have been made to model flow fronts in liquid composite molding by taking the edge effect into account. The problem of modeling resin flow through a fiber preform has been approached using Darcy's law $(1-4)$, which describes the flow of a pressurized Newtonian fluid through a porous media.

$$
Q=\frac{K}{\eta} \frac{d P}{d L}
$$

In $E q 1, Q$ is the flow rate, $K$ is the permeability of the medium, $\eta$ is the viscosity of the fluid, and $d P / d L$ is the pressure gradient. To develop this type of model, experiments must be performed to determine the permeability of the preform. This is not an easy task and has been the primary subject of several publications (5-7). Typically, the edge effect has been included in

"Corresponding author. Email address: rer@engin.umich.edu. these models by increasing the permeability near the mold wall relative to the permeability of the bulk preform. But modeling the edge effect has proven to be extremely difficult. Calhoun et al. (8) found the edge effect to be unpredictable even during controlled experiments, suggesting the edge effect to be sensitive to small variations in fabric layer misalignment, loose edge fibers, and gap size.

As mentioned, preform deformation by the injected resin may contribute to the edge effect, where deformation may occur out-of- or in-plane with respect to the preform. Out-of-plane compression has been studied by a number of authors $(6,9-12)$. Localized out-of-plane deformation has been observed by Han et al. (9) at high injection pressures near inlet gates, affecting the flow of resin in these areas. However, these gaps should close when the pressure is reduced, as the highly compressed preform returns to its original dimensions. In contrast, stable gap formation may occur during in-plane deformation of constrained preforms, exacerbating the edge effect. Friction between the clamped preform and the mold wall resists inplane motion of the preform, and therefore, gaps formed by high-pressure injection of the resin are likely to remain open when the pressure is reduced. Several models have been proposed that combine preform deformation with mold filling $(13,14)$. However, these models have not addressed the effects of preform deformation on the edge effect.

The present work focuses on the in-plane compression behavior of constrained fiber preforms. However, out-of-plane compression and frictional characteristics 


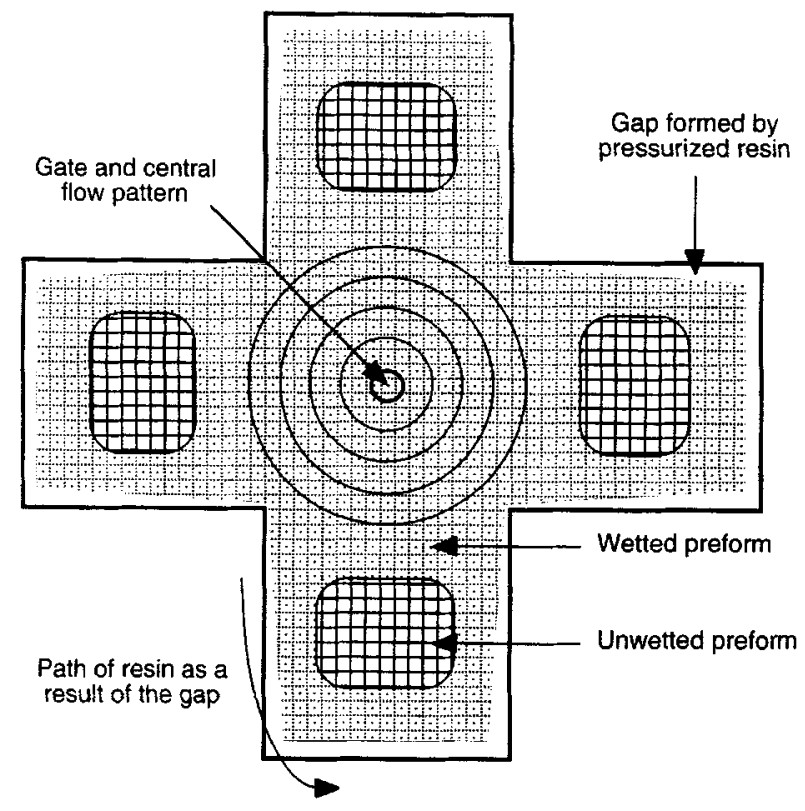

Fig. 1. Schematic of the edge effect: Preferential flow of resin through gaps between the preform and the mold wall may lead to improper preform wetting. Such gaps may be formed by in-plane compression of the preform by high-pressure injection of the resin.

have been examined, as well. The effect of a number of parameters has been studied, including preform geometry, fabric orientation, and clamping stress. These tests provide a means to measure the in-plane deformation behavior of constrained preforms, which is needed for preform deformation to be included in models used to describe the edge effect. Furthermore, a model system has been created to elucidate the interplay between preform compression and friction against the mold wall during the in-plane compression of a constrained preform.

\section{EXPERMUENTAL}

\section{Materials and Specimen Preparation}

All preforms were constructed from a plain-weave, E-glass fabric with an areal density of $0.33 \mathrm{~kg} / \mathrm{m}^{2}$ (Hexcel 7500-50 F16). 3M Super 77 spray adhesive was used as a binder. All preforms were constructed in the following steps. The fabric was cut into plies with the same dimensions and orientation of warp and weft fibers. Typically, multiple specimens were cut from a single preform to ensure consistent values of binder content and fabric orientation. Therefore, the dimensions of the plies were determined by the number and size of specimens to be cut from the preform. Approximately $2.5 \mathrm{~cm}$ was added to the length and width of the plies because the edges of the final preform required trimming. Once the plies were cut, the first ply was placed on a flat surface, and a light, uniform coat of adhesive was applied. Before the adhesive set, the next ply was placed on the previous one, taking care to match the edges and the orientation of warp and weft fibers between the two plies. Any wrinkles in the ply were smoothed, and the plies were compressed to assure complete contact between them. Subsequent plies were added using the above procedure, until all plies had been added. The adhesive was allowed to dry overnight. The edges of the preform were trimmed, and specimens were cut using an Olfa Rotary Cutter and a Craftsman Handi-Cut.

For in-plane compression experiments, "standard" specimens had the following attributes. They were made from 21 plies of fabric, oriented such that the warp fibers were parallel to the principal stress; this orientation was designated $0^{\circ} / 90^{\circ}$. The "standard" specimens were cut to a width of $51 \mathrm{~mm}$ ( 2 in.), which corresponds to the inner-width of the in-plane compression fixture (see Testing Procedures), and a length of $25 \mathrm{~mm}$ ( 1 in.). Binder content was held between 0.50 and $1.0 \mathrm{wt} \%$ for all specimens. A number of parameters were independently altered from the "standard" values during preform construction. In addition to the "standard" length, specimens were constructed with lengths of 10,51 , and $76 \mathrm{~mm}$. A second fabric orientation was included for these specimens in which the warp and weft fibers were at $45^{\circ}$ angles to the principal stress; this orientation was termed $\pm 45^{\circ}$. Specimens were constructed with 24 and 27 plies of fabric, in addition to the "standard" value of 21 . To determine if the variation in binder content had an effect on mechanical properties, specimens were constructed with binder contents of $0.35,0.50$, and 1.1 wt\%. Specimens with varying numbers of plies and binder content were constructed with a $0^{\circ} / 90^{\circ}$ fabric orientation and a length of $25 \mathrm{~mm}$.

Out-of-plane compression specimens were cut into squares with a side length of approximately $50 \mathrm{~mm}$. This geometry was chosen to ensure that the area of the specimen was greater than the area of the upper surface of the out-of-plane compression fixture (see Testing Procedures). Specimens with 21, 24, and 27 plies were constructed for out-of-plane compression experiments. Again, binder content was held between 0.50 and $1.0 \mathrm{wt} \%$.

\section{Testing Procedures}

\section{In-Plane Compression}

In-plane compression was performed with an experimental fixture that simulated the constraints placed on a preform in a closed mold (Fig. 2). The fixture is composed of two steel plates and three spacers, which bolt together, and a two-part piston. When assembled, a cavity is left for the specimen with a constant width and thickness of $50.8 \mathrm{~mm}(2 \mathrm{in}$.$) and 6.35 \mathrm{~mm}(0.25$ in.), respectively. Figure 2 shows the fixture with the front plate removed. The specimen was placed in the fixture, as shown, and the front face was bolted on, clamping the specimen. The specimen was loaded through the two pistons; one was rectangular, and the other was semicircular. The semicircular piston 


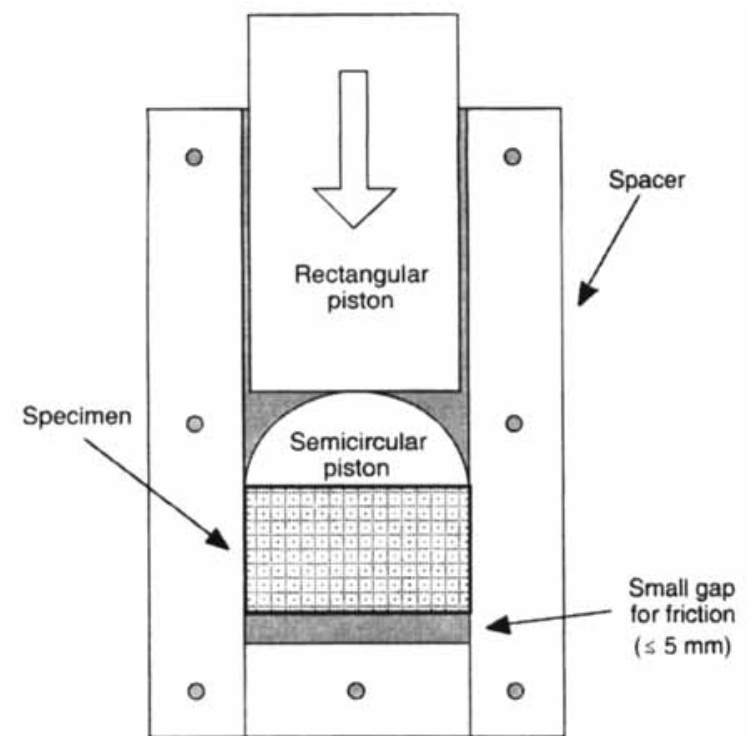

Fig. 2. Schematic of friction/in-plane compression experiment: As the specimen is driven downwards, it initially slides and then compresses.

transferred the load evenly across the top of the specimen, in case the top of the specimen was not parallel with the bottom of the rectangular piston. The rectangular piston was driven downward by a screw-driven, 4502 Instron having a $10 \mathrm{kN}$ load cell at a rate of 6.0 $\mathrm{mm} / \mathrm{min}$. A polytetrafluoroethylene mold release agent was applied to the inner-wall of the experimental fixture before each test to mimic conditions of a real molding operation. A clear, plastic face was also fabricated to view specimen deformation as it took place. To measure friction and compressive behavior in a single experiment, a small gap ( $\$ 5 \mathrm{~mm}$ ) was left between the bottom of the specimen and the floor of the fixture. As the piston was lowered, the specimen began to slide, which allowed the frictional properties to be measured. Once the bottom of the specimen reached the floor of the fixture, in-plane compression of the specimen increased. Five identical specimens were tested for each set of conditions.

\section{Out-of-Plane Compression}

Out-of-plane compression experiments were performed by compressing the specimen between flat, parallel surfaces to measure the clamping stress applied by the in-plane compression fixture. Figure 3 shows a cutaway view of the out-of-plane compression fixture. The lower surface is the flat face of a hemisphere, which has a diameter of $79.4 \mathrm{~mm}$. This hemisphere rests on a base with a concave depression; the curvature of this depression matches that of the hemisphere. This configuration allows the upper and lower surfaces to automatically adjust if the faces of the specimen are not precisely parallel. The upper surface is the face of a cylindrical piston, which is driven downwards by the Instron at a rate of $2.5 \mathrm{~mm} / \mathrm{min}$.

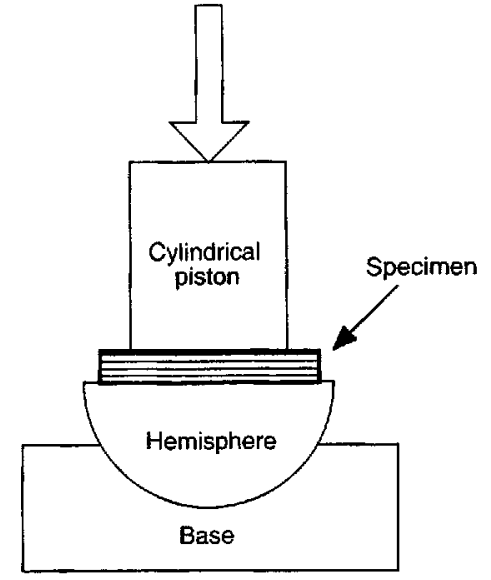

Fig. 3. Schematic of out-of-plane compression experiment.

The face of the piston has a diameter of $42.8 \mathrm{~mm}$. To measure the clamping stress imposed by the in-plane compression fixture, the specimen was compressed to a thickness of $6.35 \mathrm{~mm}$ (i.e. the inner thickness of the in-plane compression fixture). Initial tests indicated that the specimens behaved viscoelastically, so the specimens were allowed to relax for approximately five minutes before the clamping force was measured. This time allowed the majority of relaxation to occur. Viscoelastic behavior of preforms compressed out-of-plane has been observed previously $(11,12)$. The clamping stress was calculated by dividing the measured clamping force by the area of the upper surface $\left(1,440 \mathrm{~mm}^{2}\right)$. Five identical specimens were tested for each clamping stress.

\section{Cyclic Loading}

Cyclic, in-plane compression experiments were performed to examine the mechanical integrity of a specimen that had been previously loaded. For these experiments, a gap was not left between the bottom of the specimen and the floor of the fixture. A "standard" specimen was repeatedly loaded and completely unloaded, with the maximum compressive stress being increased after each cycle. Loading and unloading both took place (by driving the piston) at a rate of 6.0 $\mathrm{mm} / \mathrm{min}$; when the maximum compressive stress was reached, the direction of the piston immediately was reversed. The specimen was exposed to increasing maximum compressive stresses of $0.55,0.69,1.0$, and 2.4 MPa.

\section{RESULTS}

A typical stress versus displacement curve for a friction/in-plane compression experiment is shown in Fig. 4. Three main regions are present, corresponding to specimen sliding, elastic deformation, and severe deformation. As the piston was lowered, the static friction between the specimen and the wall of the fixture was eventually overcome, and the specimen 


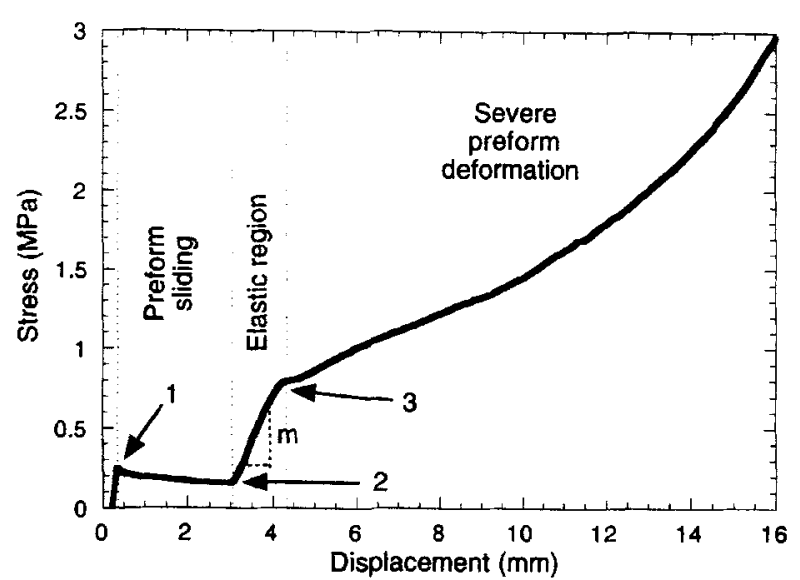

Fig. 4. Results of a typical friction/in-plane compression experiment: The specimen begins to slide at point 1, the frictional stress, and compression of the specimen begins at point 2. Severe, non-uniform deformation of the specimen begins at point 3, the maximum elastic stress. The elastic slope, $m$, is a measure of specimen stiffness.

began to slide. This occurred at point 1 and was referred to as the frictional stress. The frictional stress was used to determine the coefficient of friction between the specimen and the fixture wall. The specimen continued to slide until it reached the floor of the fixture at point 2 . The stress at point 2 was not used as a preform property because it exhibited poor reproducibility, which was attributed to transfer of the polytetrafluoroethylene mold release agent from the fixture wall to the specimen. With further downward motion of the piston, only compression of the specimen occurred. Initially, the response was linear, and the displacement over which this occurred is termed the elastic regime. The slope of the stress versus displacement curve in this region, $m$, is referred to as the elastic slope. The elastic regime ended at what is termed the maximum elastic stress, at point 3 . Above this stress and corresponding displacement, severe, permanent deformation of the specimen occurred. Clearly, parallels exist between the deformation of constrained preforms and those of a typical solid. However, it should be noted that the measured properties of constrained preforms depend on the system (e.g. geometry and clamping stress). For this reason, the measured properties, such as elastic slope, should not be thought of as material property constants because they vary with the system.

Out-of-plane compression tests were performed to measure the clamping stress exerted on the specimen by the experimental fixture. Figure 5 shows typical results. As the specimen was compressed, the load rose sharply, but if the specimen was then held at a constant thickness, the load relaxed. The majority of the relaxation occurred within $5 \mathrm{~min}$ for all specimens. Since the inner-thickness of the in-plane compression fixture was held constant $(6.35 \mathrm{~mm})$, the clamping stress was altered by varying the number of plies. The
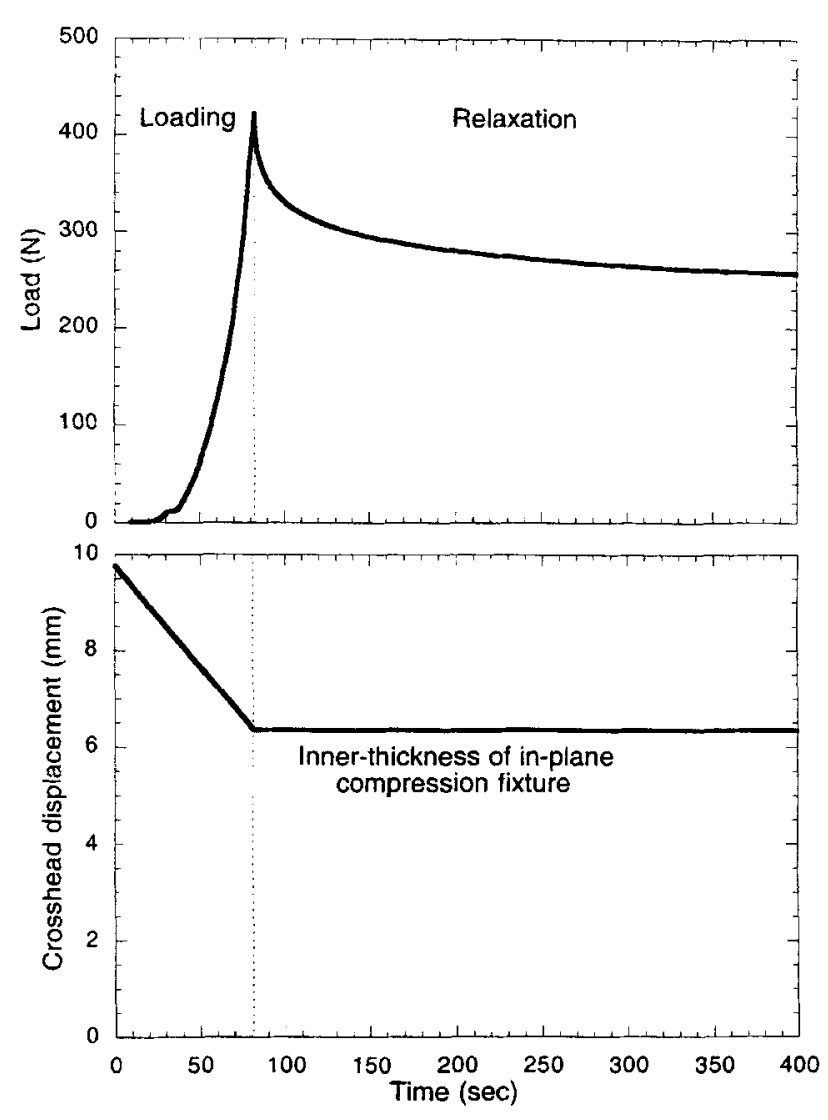

Fig. 5. Results of a typical out-of-plane compression experiment: The stress increases as the specimen is compressed. It decreases to a constant value when the specimen is held at a constant thickness.

clamping stress for specimens made with 21,24 . and 27 plies of fabric $5 \mathrm{~min}$ after compressing to the inner-thickness of the cavity in the in-plane compression fixture is shown in Table 1. The clamping stress increased with the number of plies, as expected.

Specimen deformation was viewed during the inplane compression experiments by using a clear, plastic face on the fixture. Figures 6 and 7 show examples of severely deformed specimens (i.e. deformed to well above the maximum elastic stress); the initial length of the specimens was $51 \mathrm{~mm}$. As shown in Fig. $6,0^{\circ} / 90^{\circ}$ specimens exhibited localized deformation bands, which cross the entire width of the specimen perpendicular to the applied stress. The first of these bands appeared near the top of the specimen, and others followed at regular intervals along the length of the specimen; the height of the bands is equal to the spacing between weft fibers $(\sim 2 \mathrm{~mm})$. The bands result from coordinated buckling of fibers in neighboring plies. Figure 7 shows that $\pm 45^{\circ}$ specimens also exhibit localized deformation bands. However, the bands are not perpendicular to the applied stress, and not all bands cross the entire width of the specimen. Again, the bands arise from the buckling of the fibers. Not surprisingly, the deformation in the $\pm 45^{\circ}$ and the 
Table 1. Relaxed Clamping Stresses 5 min After Compressing to $6.35 \mathrm{~mm}$.

\begin{tabular}{cc}
\hline Number of Plies & Average Clamping Stress, $\mathrm{MPa}$ \\
\hline 21 & 0.140 \\
24 & 0.504 \\
27 & 1.54 \\
\hline
\end{tabular}

$0^{\circ} / 90^{\circ}$ specimens differs, even at stresses below the maximum elastic stress. Figure 8 shows stress versus displacement curves up to the frictional stress ( 1 on Fig. 4) for $76 \mathrm{~mm}$-long specimens with the two fabric orientations. The $\pm 45^{\circ}$ specimen clearly deformed more than the $0^{\circ} / 90^{\circ}$ specimen before sliding began. Figure 9 is a plot of frictional displacement (i.e. specimen deformation before sliding occurs) versus specimen length. The frictional displacement is greater in the $\pm 45^{\circ}$ specimens than in the $0^{\circ} / 90^{\circ}$ specimens for all lengths greater than $10 \mathrm{~mm}$.

The values of stress and displacement at the points noted in Fig. 4 vary with preform construction parameters, such as specimen length, fabric orientation, and clamping stress. Figure 10 shows a plot of the frictional stress ( 1 on Fig. 4) versus specimen length for $0^{\circ} / 90^{\circ}$ and $\pm 45^{\circ}$ fabric orientations. The frictional stress increased linearly with specimen length for both fabric orientations. The $\pm 45^{\circ}$ specimens exhibited higher values of frictional stress than the $0^{\circ} / 90^{\circ}$ specimens. Figure 11 is a plot of elastic slope $(m$ on Fig. 4) versus specimen length for $0^{\circ} / 90^{\circ}$ and $\pm 45^{\circ}$ fabric orientations. The elastic slope decreased with increasing specimen length and appeared to approach a constant value for both fabric orientations. The $0^{\circ} / 90^{\circ}$ specimens showed higher values of elastic slope. Figure 12 is a plot of elastic slope versus clamping stress for $0^{\circ} / 90^{\circ}$ specimens; the clamping stress is related to the number of plies in Table 1. The elastic slope increased with clamping stress by a factor of about four over the range of clamping stress studied.

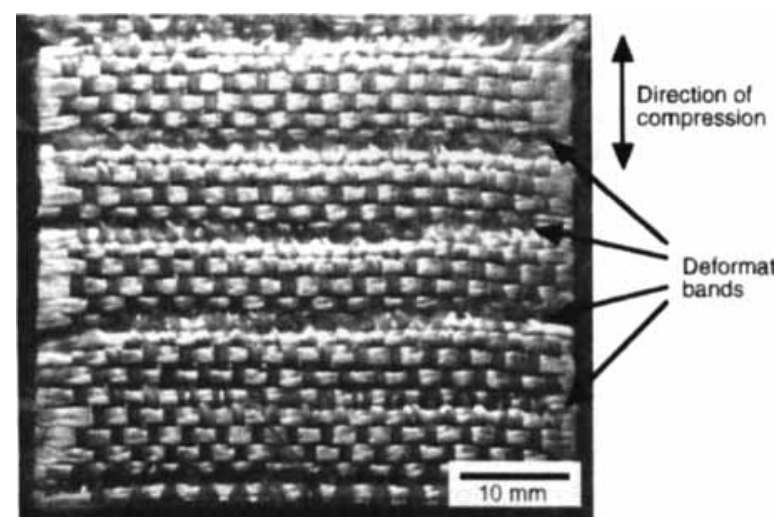

Fig. 6. Severely deformed $0^{\circ} / 90^{\circ}$ specimen of length $51 \mathrm{~mm}$ : Localized deformation bands, which cross the entire width of the specimen, are present at uniform intervals along the length of the specimen and perpendicular to the applied stress.
Figure 13 is a plot of maximum elastic stress ( 3 on Fig. 4) versus specimen length for $0^{\circ} / 90^{\circ}$ and $\pm 45^{\circ}$ specimens. Maximum elastic stress remained nearly constant, independent of specimen length. For specimen lengths of 51 and $76 \mathrm{~mm}$, considerably more scatter was found for the $\pm 45^{\circ}$ specimens than for the $0^{\circ} / 90^{\circ}$ specimens. Maximum elastic stress is plotted against clamping stress for $0^{\circ} / 90^{\circ}$ specimens in Fig. 14. Maximum elastic stress increased by a factor of six over the range of clamping stress studied.

Figure 15 shows the results of an in-plane cyclic loading experiment. In this experiment, a single, "standard" specimen was repeatedly loaded and completely unloaded, and the maximum stress (i.e. the stress at which unloading began) was increased with each cycle. In Fig. 15, the first cycle was reversed after reaching a maximum stress of $0.55 \mathrm{MPa}$, which was approximately equal to the maximum elastic stress of the specimen. In subsequent cycles, the specimen was loaded to maximum stress values of $0.69,1.0$, and $2.4 \mathrm{MPa}$, respectively. Loading and unloading are shown for the first two cycles in Fig. 15, but only portions of the loading curves are shown for the last two cycles to show the elastic region in greater detail. Figure 15 shows a decrease in the mechanical integrity of the specimen after it was loaded above its maximum elastic stress. During the first cycle, the specimen was loaded to a stress approximately equal to its maximum elastic stress, and upon reloading (i.e. second cycle), the elastic slope and maximum elastic stress are nearly equivalent to the values from the first cycle. During the second cycle, the specimen was loaded above its maximum elastic stress, and loading for the third time revealed a noticeable decrease in the elastic slope and maximum elastic stress. The first deformation band appeared during the third cycle. The fourth cycle showed an even greater decrease in the mechanical integrity of the specimen. For none of the cycles, including the first, did the specimen return to its original length when the load was completely removed.

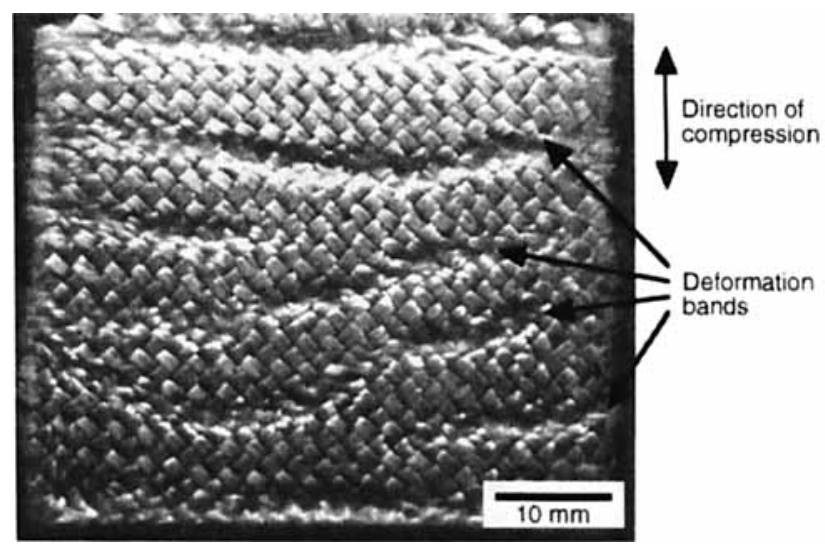

Fig. 7. Severely deformed $\pm 45^{\circ}$ specimen of length $51 \mathrm{~mm}$ : Localized deformation bands are present, which are nearly perpendicular to the applied stress. Not all bands cross the entire width of the specimen. 


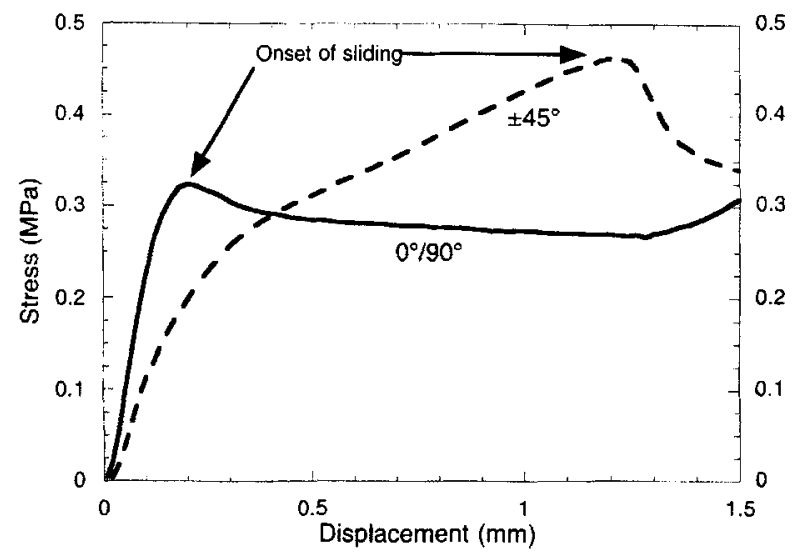

Fig. 8. Onset of sliding in $0^{\circ} / 90^{\circ}$ and $\pm 45^{\circ}$ specimens of length $76 \mathrm{~mm}$.

The binder content could not be precisely controlled and varied from 0.50 and $1.0 \mathrm{wt} \%$. To determine if this variation in binder content affected the mechanical properties, in-plane compression experiments were performed on specimens with binder contents that completely overlapped the range mentioned above $(0.35-1.1 \mathrm{wt} \%)$. Figure 16 shows the results of these experiments for $0^{\circ} / 90^{\circ}$ specimens. The data suggest that the elastic slope may increase slightly (Fig. 16a), and the maximum elastic stress may decrease slightly (Fig. 16b) with increasing binder content. But considerable overlap of the error bars can also be seen. Therefore, over this range of binder content, the binder appears not to have a sustained effect on either the elastic slope or maximum elastic stress.

\section{DIscussion}

\section{Deformation of Constrained Preforms: The Effect of Fabric Orientation}

Figures 6 and 7 show severely deformed $0^{\circ} / 90^{\circ}$ and $\pm 45^{\circ}$ specimens. These fabric orientations were chosen because they are symmetric and represent the two extreme fabric orientations with respect to the applied stress. Presumably, an intermediate fabric orientation would deform in a manner exhibiting aspects of these two. The fabric in both orientations appears to deform by buckling at stresses above the maximum elastic stress. Buckling was also observed by Fong et al. (15) during in-plane compression of thermoformable glass fiber mats. However, the orientation of the deformation bands with respect to the applied stress differs in the two fabric orientations, which may be attributed to the different orientations of the fibers.

$\pm 45^{\circ}$ specimens were shown to deform more than $0^{\circ} / 90^{\circ}$ specimens before the onset of sliding (Figs. 8 and 9). This extra deformation may be explained by a "scissoring" of the fibers in the $\pm 45^{\circ}$ specimens during in-plane compression (Fig. 17). As scissoring occurs, the specimen's length decreases, while its width increases. Therefore, if small gaps are initially present

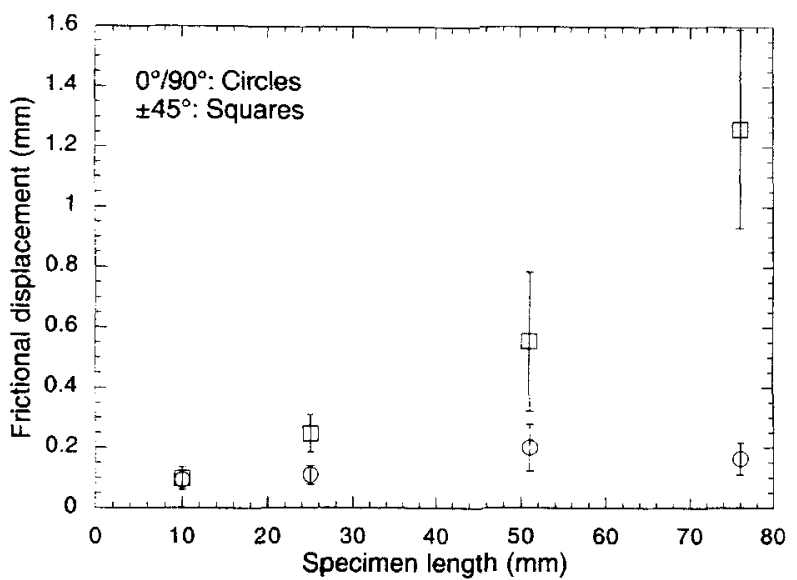

Fig. 9. The effect of specimen length on the frictional displacement for $0^{\circ} / 90^{\circ}$ and $\pm 45^{\circ}$ specimens.

between the sides of the specimen and the inner-wall of the in-plane compression fixture, scissoring may act to close these gaps, with a corresponding decrease in specimen length. Only a limited amount of scissoring may occur in $\pm 45^{\circ}$ specimens because the fibers are constrained by neighboring fibers and the walls of the fixture. Scissoring does not occur in $0^{\circ} / 90^{\circ}$ specimens because the warp fibers $\left(0^{\circ}\right)$, which support the majority of the load, are parallel with the applied stress, and the weft fibers $\left(90^{\circ}\right)$ are oriented along the width of the specimen, preventing the specimen from widening during deformation. The excessive deformation for 51 and $76 \mathrm{~mm}$ long $\pm 45^{\circ}$ specimens in Fig. 9 may also be attributed in part to the onset of buckling. The frictional stress (Fig. 1O) and the maximum elastic stress (Fig. 13) show slight overlap for these specimens, suggesting that some specimens may have reached the maximum elastic stress before sliding occurred.

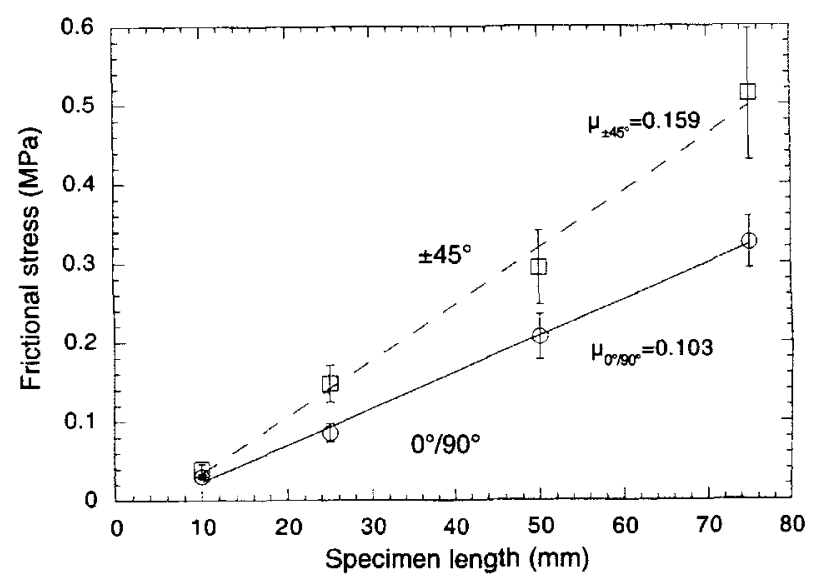

Fig. 10. The effect of specimen length on frictional stress (1 on Fig. 4) for $0^{\circ} / 90^{\circ}$ and $\pm 45^{\circ}$ specimens. The coefficient of friction between the specimen and the fixture wall may be determined from this plot. 


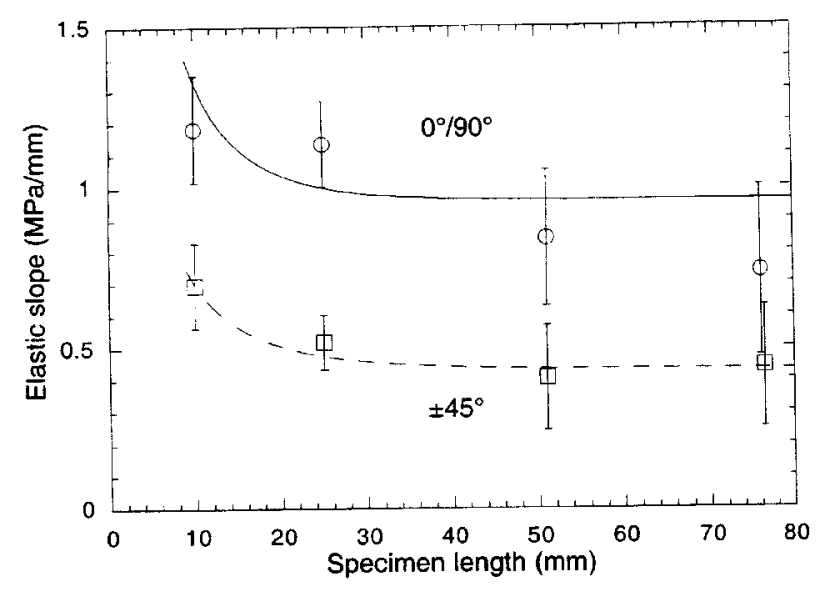

Fig. 11. The effect of specimen length on elastic slope ( $m$ on Fig. 4) for $0^{\circ} / 90^{\circ}$ and $\pm 45^{\circ}$ specimens. The curves are described by Eq 7 .

\section{Frictional Stress}

Friction plays an important role during in-plane compression of a constrained preform because specimen deformation cannot occur without at least some part of the specimen sliding within the fixture. The frictional stress ( 1 in Fig. 4) was observed to increase linearly with specimen length (Fig. 10). Since a gap existed initially between the bottom of the specimen and the floor of the fixture, the frictional stress is typically dominated by friction between the specimen and the fixture walls (i.e. specimen deformation is expected to be small). Figure 9 shows that minimal deformation $(\sim 0.1 \mathrm{~mm}$ ) occurred before sliding began with the $0^{\circ} / 90^{\circ}$ specimens, irrespective of length. The deformation increased with specimen length before sliding began with the $\pm 45^{\circ}$ specimens. The frictional stress, $\sigma_{f}$ can be converted to frictional force, $F_{f}$, by multiplying by the cross-sectional area of the specimen, $A_{X}$.

$$
\sigma_{f} A_{x}=F_{f}=\mu N
$$

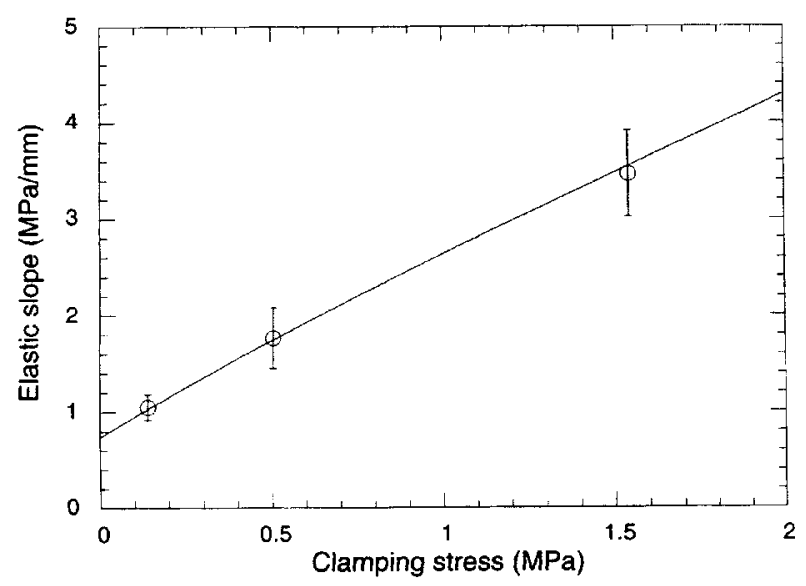

Fig. 12. The effect of clamping stress on elastic slope ( $m$ on Fig. 4) for $0^{\circ} / 90^{\circ}$ specimens. The curve is described by Eq 11.
The frictional force is equal to the static coefficient of friction, $\mu$, times the normal force, $N$, which is the product of the clamping stress, $\sigma_{\text {clamping, }}$ and the contact area between the specimen and the fixture wall, $A_{\text {contact }}$

$$
N=\sigma_{\text {clamping }} A_{\text {contact }}
$$

The contact area is proportional to specimen length because the specimen width is fixed, and therefore, a linear relationship between frictional force and specimen length exists. Furthermore, the coefficient of friction may be determined from a plot of frictional force versus normal force by measuring the slope. This gives $\mu$ values of 0.103 and 0.159 for $0^{\circ} / 90^{\circ}$ and $\pm 45^{\circ}$, respectively. The larger value of $\mu$ for the $\pm 45^{\circ}$ specimens probably arises from scissoring, which causes the specimen to widen, compressing the specimen against the side walls of the cavity.

\section{Elastic Slope}

\section{Elastic Slope Versus Length}

Elastic slope ( $\mathrm{m}$ in Fig. 4) is a measure of preform deformation within the elastic region. The elastic slope was found to decrease with specimen length, appearing to approach a constant value at large specimen lengths (Fig. 11). In the absence of friction, the elastic slope, $m$, is expected to be inversely proportional to specimen length, $L$, for

$$
\Delta \sigma=m \Delta L=E \Delta \varepsilon
$$

where $\Delta \sigma$ is the stress increment, $\Delta L$, is the displacement, $E$ is the elastic modulus, and $\Delta \varepsilon$ is the strain increment, which may be defined as

$$
\Delta \varepsilon=\frac{\Delta L}{L}
$$

Hence,

$$
m=\frac{E}{L}
$$

Were $E q 6$ to describe elastic slope, $m$ would decrease monotonically with $L$. Instead, $m$ becomes constant at sufficiently long lengths. However, friction between the specimen and the fixture is present and is expected to modify the specimen length dependence.

As is shown in the Appendix, when friction is present and when the in-plane stress also contributes to the frictional resistance to movement, $m$ is given by

$$
m=\frac{E_{\mu} C a}{A_{X}}\left(1-e^{-\frac{\mu C a}{A_{X}} L}\right)^{-1}
$$

where $E$ is the modulus of the specimen, $\mu$ is the friction coefficient between the specimen and the fixture, $C$ is the circumference of the specimen, $a$ is a measure of the degree to which the compressive stress contributes to the frictional resistance, $A_{X}$ is the cross-sectional area normal to the applied in-plane force, and $L$ is the specimen length. If desired, the friction coefficient, circumference, and the coefficient 


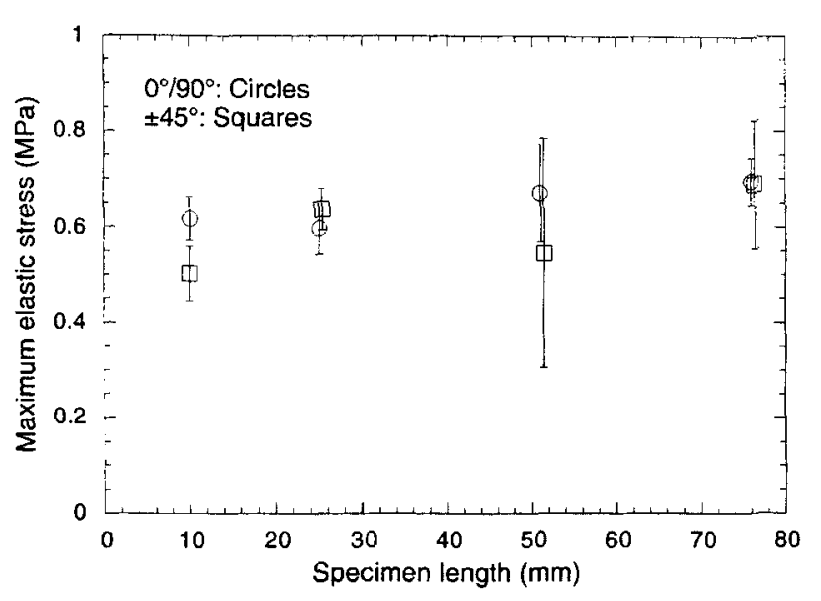

Fig. 13. The effect of specimen length on maximum elastic stress (3 on Fig. 4) for $0^{\circ} / 90^{\circ}$ and $\pm 45^{\circ}$ specimens.

$a$ can be given as a sum of products specific to the faces and to the sides of the specimen, respectively. Because of lack of data, however, this separation was not done here. The major implication of this model is that deformation occurs within a finite region of the specimen adjacent to the loaded end.

According to $\mathrm{Eq} 7$, when $\mu \mathrm{CaL} / A_{X}$ is small, the expression for elastic slope reverts to $E q$, as expected. When $\mu \mathrm{CaL} / \mathrm{A}_{\mathrm{X}}$ is large, the exponential term becomes negligible, and the expression for elastic slope becomes independent of specimen length ( $E q$ 8).

$$
m=E \frac{\mu C a}{A_{X}}
$$

Hence, the elastic slope decreases with length to a constant value greater than zero, which is the general shape of the elastic slope versus specimen data in Fig. 11.

Equation 7 was used to model the results of Fig. 11 by choosing values of $E$ and $a$ that provided the best fit. The calculated values of the elastic slope are included on Fig. 11, and the calculations were made using $E$ and $a$ values of $7.5 \mathrm{MPa}$ and 3.5 for $0^{\circ} / 90^{\circ}$ specimens and $4.5 \mathrm{MPa}$ and 1.7 for $\pm 45^{\circ}$ specimens. The values for the remaining parameters came directly from the specimen geometry except $\mu$, which was measured.

\section{Elastic Slope Versus Fabric Orientation}

In Fig. 11 , the $0^{\circ} / 90^{\circ}$ specimens exhibited greater values of elastic slope than did the $\pm 45^{\circ}$ specimens. Since the frictional constraint in the $\pm 45^{\circ}$ specimens was found to be greater than in the $0^{\circ} / 90^{\circ}$ specimens (Fig. 1O), a higher elastic slope might be expected from the $\pm 45^{\circ}$ specimens. However, the relative orientation of fibers with respect to the applied stress should have an effect on the elastic slope, as well. For $0^{\circ} / 90^{\circ}$ specimens, the warp fibers $\left(0^{\circ}\right)$ were oriented in the direction of the applied stress, allowing these fibers to carry a majority of the stress. In contrast, $\pm 45^{\circ}$ specimens

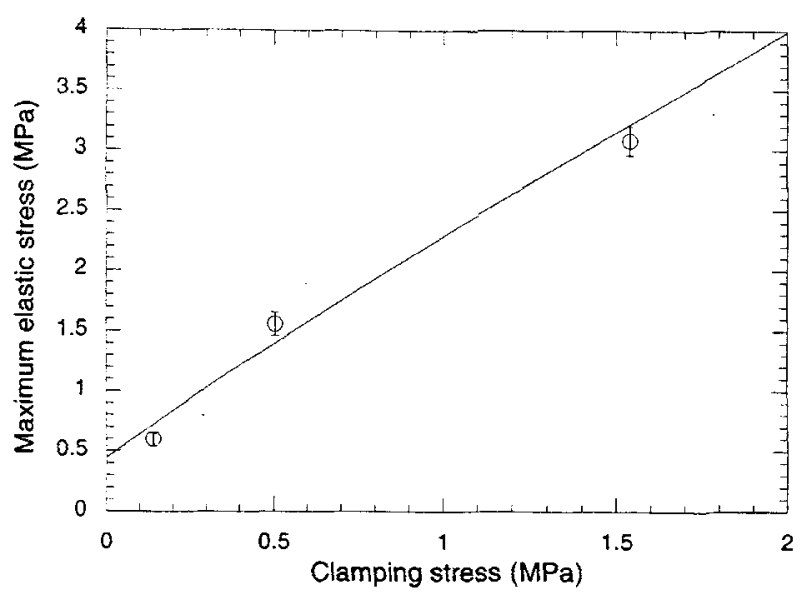

Fig. 14. The effect of clamping stress on maximum elastic stress (3 on Fig. 4) for $0^{\circ} / 90^{\circ}$ specimens. The curve is described by Eq 14.

have fibers oriented $45^{\circ}$ away from the applied stress, and therefore, they are not able to support the stress as efficiently. Furthermore, scissoring of the fibers occurs within the elastic regime, also contributing to the lower elastic slope for these specimens.

\section{Elastic Slope Versus Clamping Stress}

Elastic slope increases with clamping stress (Fig. 12) as a result of two mechanisms. First, by squeezing the preform in the thickness dimension, increased clamping stress increases the volume fraction of reinforcement. This increases the elastic slope because a larger stress is needed to deform the greater number of load bearing fibers per unit volume. Second, clamping stress increases the frictional force, $F_{f}$, between the specimen and the fixture wall (Eqs 2 and 3). Friction between the specimen and the fixture wall has been shown to affect the elastic slope (Fig. 11), and since the friction resists deformation, an increase in the friction should increase the elastic slope.

The volume fraction of reinforcement, $V_{f}$ is given by

$$
V_{f}=\frac{n \rho_{\text {areal }}}{t \rho_{\text {glass }}}
$$

where $n$ is the number of plies, $p_{\text {areal }}$ is the areal density of the fabric $\left(0.33 \mathrm{~kg} / \mathrm{m}^{2}\right), t$ is the clamped thickness of the specimen, and $\rho_{\text {glass }}$ is the density of glass $\left(2.56 \mathrm{~g} / \mathrm{cm}^{3}\right)$. The increase in the volume fraction of reinforcement with respect to clamping stress is shown in Fig. 18.

As mentioned earlier, elastic slope varies with clamping stress (Fig. 12) because the clamping stress affects the volume fraction of reinforcement within the specimen and the friction between the specimen and the fixture wall. Therefore, the model of elastic slope as a function of clamping stress is based on these two mechanisms. To include the change in volume fraction with clamping stress in the model, the data in Fig. 18 were fitted with the following equation. 


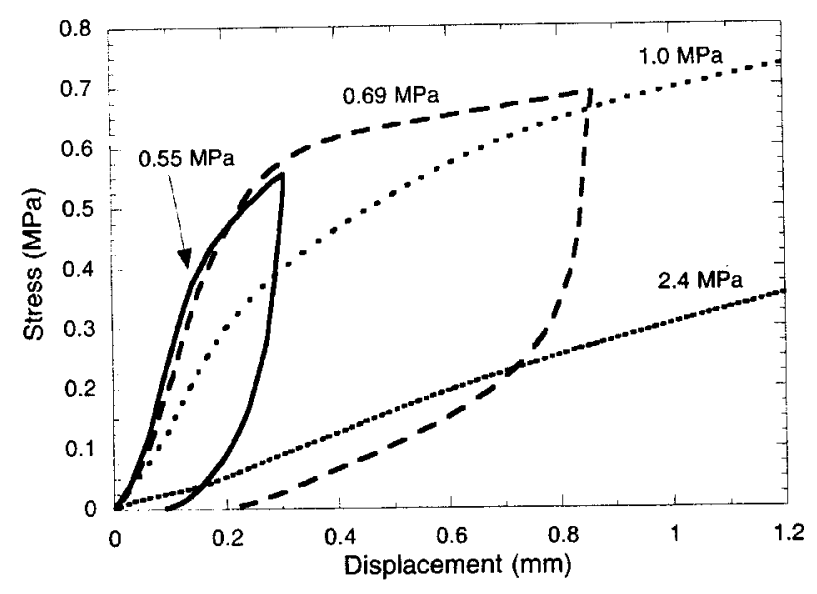

Fig. 15. Results of a typical cyclic loading experiment: A single, "standard" specimen is repeatedly loaded and unloaded to an increasing maximum stress (0.55-2.4 MPa). As the maximum stress exceeds the maximum elastic stress ( 3 on Fig. 4), the elastic slope ( $m$ on Fig. 4) and maximum elastic stress decrease upon reloading.

$$
\begin{aligned}
& V\left(\sigma_{\text {clamping }}\right)=V_{f, \max }- \\
& \left(V_{f, \text { max }}-V_{f, \text { min }}\right) \exp \left(-b \sigma_{\text {clamping }}\right)
\end{aligned}
$$

in which $V_{f, \min }$ and $V_{f, \max }$ are the minimum and maximum volume fractions of reinforcement and $b$ is a constant. $V_{f, \min }$ is simply the volume fraction of reinforcement in the unclamped specimen (0.37), and $V_{f, \max }$ is the volume fraction of reinforcement at very high clamping stress. For close-packed, parallel fibers with equal radii, $V_{f, \max }$ would approach 0.91 , but stacks of a plain-weave fabric should have significantly less efficient packing. The best fit to the data was obtained with the values of 1.25 and 0.60 for $b$ and $V_{f, \max }$, respectively. The effect of clamping stress on the friction between the specimen and the fixture wall was included by using Eqs 2 and 3.

The model assumes that terms proportional to the frictional force and volume fraction of reinforcement add to give the elastic slope. The volume fraction of reinforcement should be related to the elastic slope through the "rigidity" of the fibers, which is the modulus of the fibers, $E$, divided by the specimen length, $L$. The frictional force, $F_{f}$, can be related to the elastic slope by dividing by the specimen volume, $V$, since the elastic slope may be thought of as a force over a given volume. This leads to

$$
m\left(\sigma_{\text {clamping }}\right)=c_{1} \frac{E}{L} V_{f}\left(\sigma_{\text {clamping }}\right)+c_{2} \frac{F_{f}\left(\sigma_{\text {clamping }}\right)}{V}
$$

where $c_{1}$ and $c_{2}$ are constants. Values of $6.77 \times 10^{-4}$ and 48.26 for $c_{1}$ and $c_{2}$ resulted in the best fit for the data in Fig. 12. Since these data are nearly linear, this suggests that the frictional component has a greater impact on the elastic slope than does the reinforcement volume fraction.
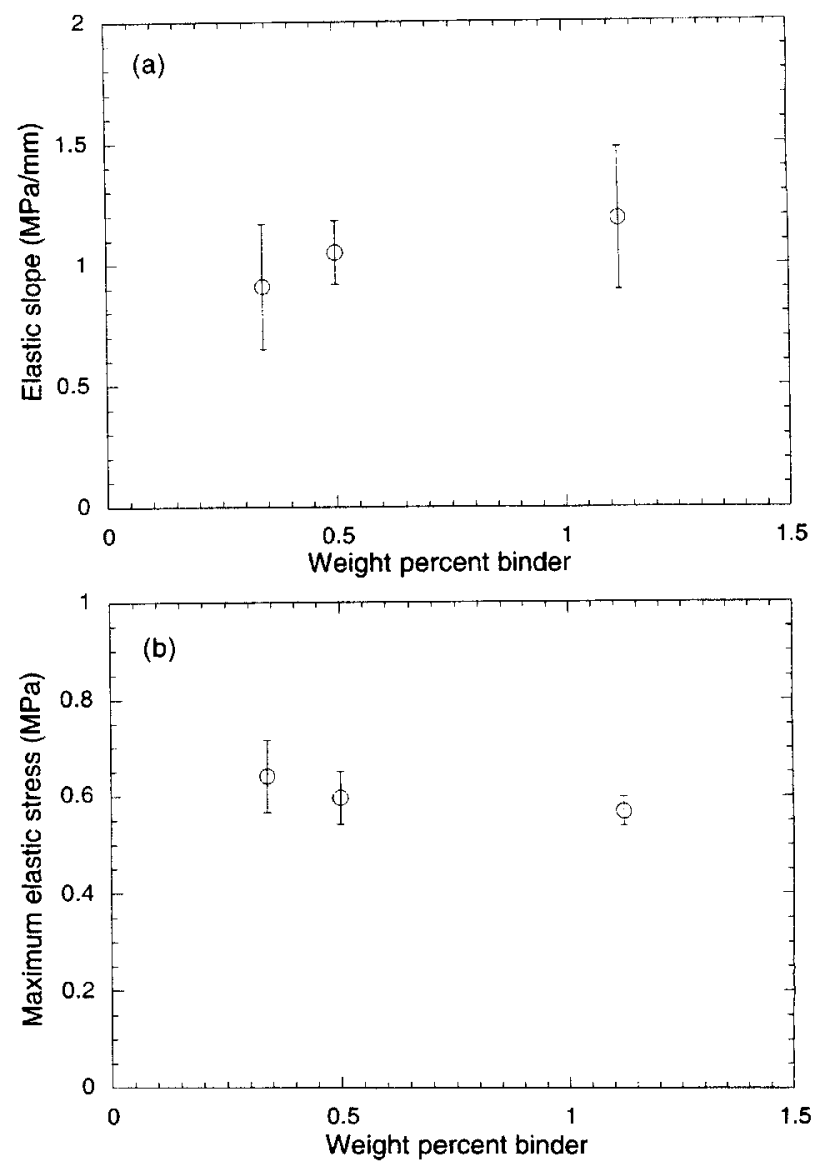

Fig. 16. a) The effect of binder content on elastic slope ( $m$ on Fig. 4), and b) the effect of binder content on the maximum elastic stress ( 3 on Fig. 4) for $0^{\circ} / 90^{\circ}$ specimens.

\section{Maximum Elastic Stress}

The maximum elastic stress ( 3 on Fig. 4) is the upper limit of the elastic regime. Above this value, two phenomena occur. The amount of specimen deformation per unit stress increment increases, and the preform sustains permanent structural damage. Typical damage above the maximum elastic stress is shown in Figs. 6 and 7 for $0^{\circ} / 90^{\circ}$ and $\pm 45^{\circ}$ specimens in the form of buckling. Cyclic loading experiments provide further insight into the damage sustained above this critical stress. Figure 15 shows that once a specimen has been loaded above its maximum elastic stress, its mechanical integrity degrades. On reloading, the elastic slope and maximum elastic stress are less. Cyclic loading experiments also demonstrated that localized buckling occurs at a stress just above the maximum elastic stress. Therefore, to minimize preform deformation and maintain the mechanical integrity of components, the applied stress should not exceed the maximum elastic stress.

\section{Maximum Elastic Stress Versus Preform Length}

A plot of maximum elastic stress versus specimen length (Fig. 13) shows the maximum elastic stress to 
Fig. 17. Schematic of fiber scissoring in $\pm 45^{\circ}$ specimens: Under an applied load, the length of the specimen decreases, and the width of the specimen increases.
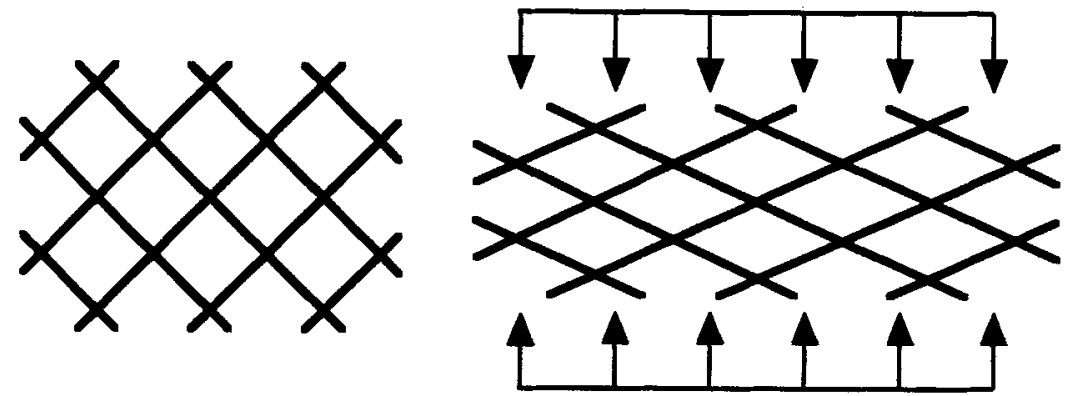

be nearly independent of specimen length for both $0^{\circ} / 90^{\circ}$ and $\pm 45^{\circ}$ specimens. These results, as well as those from the cyclic loading experiments, suggest that the maximum elastic stress corresponds to the onset of preform damage. As shown in Figs. 6 and 7 , damage occurs in the form of localized buckling, which begins near the top of the specimen and follows at regular intervals along the length of the specimen. In Fig. 13, there is considerable scatter in the data for $\pm 45^{\circ}$ specimens with lengths of 51 and $76 \mathrm{~mm}$. This may have occurred because the frictional stress (Fig. 10) approaches the maximum elastic stress (Fig. 13) for large specimen lengths. The frictional stress increases proportionally with preform length, while the maximum elastic stress is independent of preform length. Therefore, with increasing preform length, the frictional stress is expected to reach the maximum elastic stress. At this point, damage to the preform is expected before sliding occurs.

\section{Maximum Elastic Stress Versus Clamping Stress}

Maximum elastic stress increases with clamping stress (Fig. 14). This phenomenon may be explained using the same basic ideas for the increase in elastic slope with clamping stress. The volume fraction of reinforcement increases with clamping stress (Fig. 18), and therefore, it takes a larger stress to damage the greater number of load-bearing fibers per unit volume. The clamping stress is also proportional to the friction between the preform and the fixture wall (Eqs 2 and 3). The maximum elastic stress appears to be independent of friction between the specimen and the fixture wall (Fig. 13), but it should be affected by the friction between the plies within the specimen. Localized buckling begins at the maximum elastic stress, and the plies within the specimen must slide past one another for buckling to occur. The clamping stress should be proportional to the frictional force required for the plies to slide past one another.

The maximum elastic stress as a function of clamping stress was modeled in a similar fashion to the elastic slope as a function of clamping stress. The volume fraction of reinforcement was included through Eq 10, while the friction between plies was included using Eqs 2 and 3. However, in this case, $\mu$ and $A_{\text {con- }}$ tact refer to the coefficient of friction and contact area between the plies, as they slide past one another. The model assumes that terms proportional to the frictional force and volume fraction of reinforcement add to give the maximum elastic stress. The volume fraction of reinforcement within the specimen was related to the maximum elastic stress through the Euler buckling stress for the individual fibers, $\sigma_{b}$.

$$
\sigma_{b}=\frac{\pi^{2} E}{16}\left(\frac{d_{f}}{L_{f}}\right)^{2}
$$

where $E$ is the modulus of the fibers, $d_{f}$ is the diameter of the fiber, and $L_{f}$ is the length along which the fiber buckles. The buckling length equals the height of the localized deformation bands $(\sim 2 \mathrm{~mm})$. To quantify the frictional force, $F_{f}$ between the plies, $A_{\text {contact }}$ was calculated as

$$
A_{\text {contact }}=(n-1) w L_{f}
$$

where $n$ is the number of plies, $w$ is the width of the specimen, and $L_{f}$ is the buckling length. The frictional force was related to the maximum elastic stress by dividing by the cross-sectional area of the specimen, $A_{\mathrm{X}}$. This results in the following expression for maximum elastic stress, MES, as a function of clamping stress.

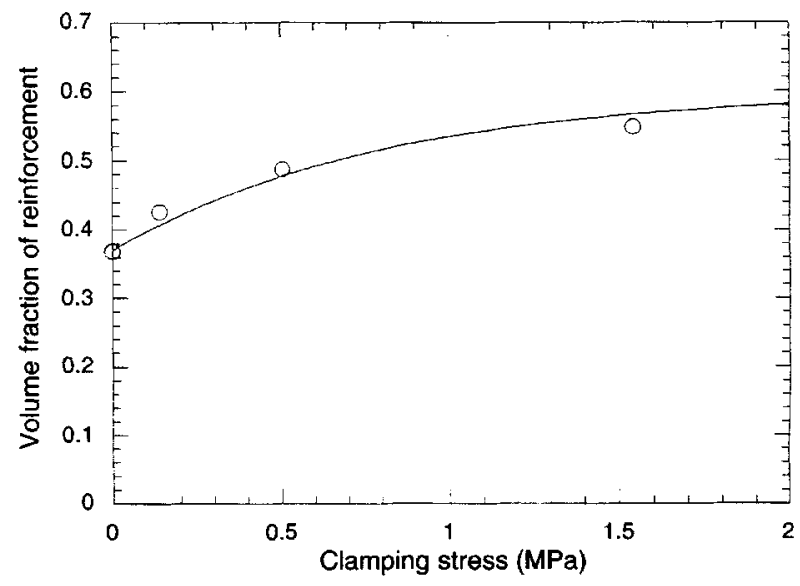

Fig. 18. The effect of clamping stress on the volume fraction of reinforcement within the specimen. The curve is described by Eq 10. 


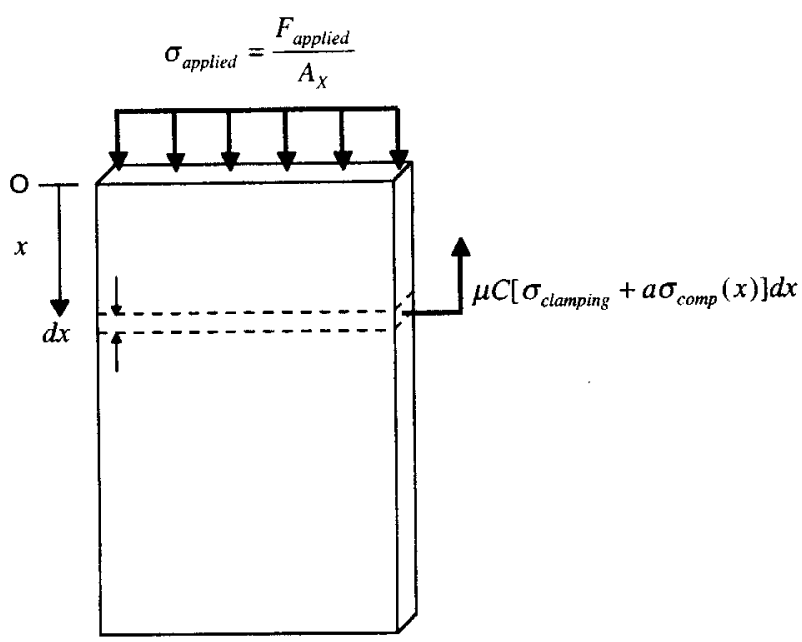

Fig. 19. Schematic of the model used to predict preform deformation within the elastic regime. A stress, $\sigma_{\text {applied, }}$ is transmitted to the top of the specimen $(x=0)$. Part of this stress is used to overcome the friction between the specimen and the fixture wall, and the remainder is used to compress the preform.

$$
\operatorname{MES}\left(\sigma_{\text {clamping }}\right)=e_{1} \sigma_{b} V_{f}\left(\sigma_{\text {clamping }}\right)+e_{2} \frac{F_{f}\left(\sigma_{\text {clamping }}\right)}{A_{X}}
$$

where $e_{1}$ and $e_{2}$ are constants. Assuming a coefficient of friction of 0.3 between the plies of the specimen, $e_{1}$ and $e_{2}$ values of 0.86 and 0.90 give the best fit to the data using Eq. 14. Since the data in Fig. 14 are nearly linear, this suggests that the frictional component has a greater impact on maximum elastic stress than the contribution of the volume fraction of reinforcement.

\section{CONCLUSIONS}

When subjected to in-plane compression, constrained preforms behave in a predictable fashion up to the maximum elastic stress ( 3 on Fig. 4). Above this stress, buckling of the preform ensues, which compromises the mechanical integrity of the preform and results in severe deformation. Therefore, preform deformation, and the edge effect, may be reduced by keeping the pressure of the injected resin below the maximum elastic stress. Before the maximum elastic stress is reached, preform deformation is proportional to the applied stress via the elastic slope (m on Fig. 4). Maximum elastic stress and elastic slope vary with specimen geometry and clamping stress, which alters the frictional constraint imposed on and the volume fraction of reinforcement within the preform. However, increasing clamping stress decreases the permeability of the preform, which may exacerbate the edge effect. Orienting fabric so the fibers are aligned with the applied stress provides superior resistance to deformation. Lack of alignment between fibers and the applied stress leads to scissoring of the fabric, which results in significant deformation at low applied stress. Furthermore, since preform deformation below the maximum elastic stress is predictable, it may be relatively simple to include it in models that predict the edge effect during liquid composite molding.

\section{APPENDIX: MODEL FOR ELASTIC SLOPE VERSUS SPECHMEN LENGTE}

The mechanical stresses acting on a preform specimen when a downward-acting in-plane force is imposed are indicated in Fig. 19. The in-plane compressive stress acting at the upper surface of the preform is $\sigma_{\text {applied }}=F_{\text {applied }} / A_{X}$, where $F_{\text {applied }}$ is the force, and $A_{X}$ is the cross-sectional area; this reacts against the friction forces acting on the lateral surfaces of the preform, as well as any upward in-plane force acting at the bottom of the specimen. The friction force, $\mu \mathrm{C}$ $\left[\sigma_{\text {clamping }}+a \sigma_{\text {comp }}(x)\right] d x$, is shown explicitly in Fig. 19 only for the incremental length of specimen, $d x$, located a distance $x$ from the top surface. In this expression, $\mu$ is the friction coefficient, $C$ is the circumference of the specimen, $\sigma_{\text {clamping }}$ is the clamping stress, $\sigma_{\text {comp }}(x)$ is the downward-acting in-plane compressive stress at $x$, and $a$ is a measure of the degree to which the compressive stress contributes to the frictional resistance. The in-plane compressive force, $F_{\text {comp }}$, acting on any horizontal plane in the specimen at a distance $x$ from the upper surface is then

$$
\begin{aligned}
& F_{\text {comp }}(x)=A_{X} \sigma_{\text {comp }}(x)= \\
& F_{\text {applied }}-\int_{0}^{x} \mu C\left[\sigma_{\text {clamping }}+a \sigma_{\text {comp }}(x)\right] d x
\end{aligned}
$$

If desired, the friction coefficient, circumference, clamping stress, and the coefficient $a$ can be given as a sum of products specific to the faces and to the sides of the specimen, respectively. Because of lack of data, however, this separation will not be done here.

Equation $A l$ can be turned into a differential equation for $\sigma_{\text {comp }}(x)$ by differentiating it with respect to $x$, giving

$$
\frac{d \sigma_{\text {comp }}}{d x}=-\frac{1}{A_{X}}\left\{\mu C\left[\sigma_{\text {clamping }}+a \sigma_{\text {comp }}(x)\right]\right\}
$$

To solve this equation, $\sigma_{\text {comp }}(x)$ can be assumed to have the form

$$
\sigma_{\text {comp }}(x)=G e^{-J x}+H
$$

which gives

$$
\frac{d \sigma_{c o m p}}{d x}=J G e^{-J x}=-J\left(\sigma_{c o m p}(x)-H\right)
$$

By comparing Eq A4 with $E q A 2, J$ and $H$ are seen to be given by 


$$
\begin{gathered}
J=\frac{\mu C a}{A_{X}} \\
H=-\sigma_{\text {clamping }} / a
\end{gathered}
$$

$$
\text { At } \begin{aligned}
& x=0, \sigma_{\text {comp }}(0)= \\
& G-\sigma_{\text {clamping }} / a=F_{\text {applied }} / A_{X}, \text { giving } \\
& G=\frac{F_{\text {applied }}}{A_{X}}+\frac{\sigma_{\text {clamping }}}{a}
\end{aligned}
$$

Hence, the downward-acting, in-plane compressive stress at any location within the specimen is given by

$$
\sigma_{\text {comp }}(x)=\left(\frac{F_{\text {applied }}}{A_{X}}+\frac{\sigma_{\text {clamping }}}{a}\right) e^{-\frac{\mu C Q}{A_{X}} x}-\frac{\sigma_{\text {clamping }}}{a}
$$

If the in-plane force, $F_{\text {applied }}$, is incrementally increased, the in-plane stress increases according to

$$
\Delta \sigma_{\text {comp }}(x)=\frac{\Delta F_{\text {applled }}}{A_{X}} e^{-\frac{\mu C a}{A_{X}} x}
$$

The corresponding change in displacement is given by

$$
\begin{aligned}
\Delta L & =\int_{0}^{L} \Delta \varepsilon d x=\int_{0}^{L} \frac{\Delta \sigma_{\text {comp }}(x)}{E} d x \\
& =\frac{\Delta F_{\text {applied }}}{E A_{X}} \frac{A_{X}}{\mu C a}\left(1-e^{-\frac{\mu C a}{A_{X}} L}\right)
\end{aligned}
$$

where $E$ is the elastic modulus of the preform. Because the elastic slope, $m$, equals

$$
\begin{aligned}
& \left(\Delta F_{\text {applied }} / A_{X}\right) / \Delta L \\
& \qquad m=\frac{E \mu C a}{A_{X}}\left(1-e^{-\frac{\mu C a}{A_{X}} L}\right)^{-1}
\end{aligned}
$$

The major implication of this model is that deformation occurs within a finite region of the specimen adjacent to the loaded end. This is apparent from $E q$ A5, in which $\sigma_{\text {comp }}(x)$ decreases with increasing $x$, when $\sigma_{\text {comp }}(x)$ reaches zero, the specimen no longer deforms.

\section{ACENOWLEDGMENTS}

The authors would like to thank Prof. K. Jayaraman and Mr. Jason Chaneske, Department of Chemical

\begin{tabular}{|c|c|}
\hline$A_{\text {contact }}$ & Contact area \\
\hline$A_{X}$ & Cross-sectional area \\
\hline$a$ & Constant \\
\hline$b$ & Constant \\
\hline$c$ & Circumference \\
\hline$c_{1}$ & Constant \\
\hline$c_{2}$ & Constant \\
\hline $\bar{d}_{f}$ & Fiber diameter \\
\hline$E$ & Modulus of elasticity \\
\hline$e_{1}$ & Constant \\
\hline$e_{2}$ & Constant \\
\hline$F_{\text {applied }}$ & Applied force \\
\hline$F_{\text {comp }}$ & Compressive force \\
\hline$F_{f}$ & Frictional force \\
\hline$G$ & Integration parameter \\
\hline$H$ & Integration parameter \\
\hline$J$ & Integration parameter \\
\hline$K$ & Permeability \\
\hline$L$ & Length \\
\hline$L_{f}$ & Fiber length \\
\hline MES & Maximum elastic stress \\
\hline$m$ & Elastic slope \\
\hline$N$ & Normal force \\
\hline$n$ & Number of plies \\
\hline$P$ & Pressure \\
\hline$Q$ & Flow rate \\
\hline$t$ & Thickness \\
\hline$V$ & Volume \\
\hline$V_{f}$ & Volume fraction of reinforcement \\
\hline$V_{f, \max }$ & $\begin{array}{l}\text { Maximum volume fraction of rein- } \\
\text { forcement }\end{array}$ \\
\hline$V_{f, \min }$ & $\begin{array}{l}\text { Minimum volume fraction of rein- } \\
\text { forcement }\end{array}$ \\
\hline$w$ & Width \\
\hline$x$ & Distance from the top of the preform \\
\hline $\boldsymbol{\varepsilon}$ & Strain \\
\hline$\eta$ & Viscosity \\
\hline$\mu$ & Coefficient of friction \\
\hline$\rho_{\text {areal }}$ & Areal density \\
\hline$P_{\text {glass }}$ & Density of glass \\
\hline$\sigma$ & Stress \\
\hline$\sigma_{b}$ & Buckling stress \\
\hline$\sigma_{\text {clamping }}$ & Clamping stress \\
\hline$\sigma_{\text {comp }}$ & Compressive stress \\
\hline $\boldsymbol{\sigma}_{f}$ & Frictional stress \\
\hline
\end{tabular}
Engineering, Michigan State University, for their collaboration on this work and Hexcel Corp. for their generous donation of materials. This research was supported in part by the National Science Foundation/State/Industry/University Cooperative Research Center for High-Speed, Low-Cost Composite Processing at Michigan State University, NSF Grant No. EEC 9108846, Ford Motor Company, and by the Michigan Materials and Processing Institute.

\section{NOMENCLATURE}

REFERENCES

1. C. J. Wu, L. W. Hourng, and J. C. Liao., J. Reinf. Plast. Compos., 14, 694 (1995).

2. C. J. Wu and L. W. Hourng. Polym. Eng. Sci, 95, 1272 (1995).

3. W. B. Young and C. L. Lai, Composites: Part A, 28A, 817 (1997).

4. A. Hammami, R. Gauvin, and F. Trochu. Composites: Part A, 28A, 603 (1998).

5. T. J. Wang, C. H. Wu, and L. J. Lee, Polym. Compos., 15, 278 (1994).

6. C. D. Rudd, L. J. Bulmer, D. J. Morris, and K. N. Kendall. Mater. Sci. Technol, 12, 436 (1996). 
David A. Norman, Jae-Ho Kim, and Richard E. Robertson

7. C. L. Lai and W. B. Young, Polym. Compos., 18, 642 (1997).

8. D. R. Calhoun, S. Yalvaç, D. G. Wetters, and C. A Raeck, Polym. Compos., 17, 11 (1996).

9. K. Han, L. Trevino, L. J. Lee, and M. Liou, Polym. Com pos., 14, 144 (1993).

10. R. S. Parnas, C. R. Scheltheisz, and S. Ranganathan. Polym. Compos., 17, 4 (1996).

11. Y. R. Kim and S. P. McCarthy, Polym. Compos., 12, 13 (1991).
12. F. Robitaille and R. Gauvin, Polym. Compos., 18, 543 (1998).

13. K. Han, L. Trevino, L. J. Lee, and M. Liou, Polym Com pos., 14, 151 (1993).

14. D. Ambrosi and L. Preziosi, Composites: Part A, 29A, 5 (1998).

15. L. Fong, J. Xu, and L. J. Lee, Polym. Compos., 15, 134 (1994). 